\title{
Blockade of interleukin- 6 signalling with siltuximab enhances melphalan cytotoxicity in preclinical models of multiple myeloma
}

\author{
Sally A. Hunsucker ${ }^{1}$, Valeria Magarotto ${ }^{1}$, Deborah J. Kuhn ${ }^{1}$, Steven M. Kornblau ${ }^{2,3}$, Michael \\ Wang $^{1}$, Donna M. Weber ${ }^{1}$, Sheeba K. Thomas ${ }^{1}$, Jatin J. Shah ${ }^{1}$, Peter M. Voorhees ${ }^{4}$, Hong \\ Xie $^{5}$, Mark Cornfeld ${ }^{5}$, Jeffrey A. Nemeth ${ }^{5}$, and Robert Z. Orlowski ${ }^{1,6}$ \\ ${ }^{1}$ Department of Lymphoma and Myeloma, The University of Texas M. D. Anderson Cancer \\ Center, Houston, TX \\ ${ }^{2}$ Department of Stem Cell Transplantation and Cellular Therapy, The University of Texas M. D. \\ Anderson Cancer Center, Houston, TX \\ ${ }^{3}$ Department of Leukemia, The University of Texas M. D. Anderson Cancer Center, Houston, TX \\ ${ }^{4}$ The University of North Carolina at Chapel Hill Lineberger Comprehensive Cancer Center, \\ Chapel Hill, NC \\ ${ }^{5}$ Centocor Ortho Biotech, Inc., Horsham, PA \\ ${ }^{6}$ Department of Experimental Therapeutics, Division of Cancer Medicine, The University of Texas \\ M. D. Anderson Cancer Center, Houston, TX, USA
}

\section{Summary}

\begin{abstract}
Signalling through the interleukin (IL)-6 pathway induces proliferation and drug resistance of multiple myeloma cells. We therefore sought to determine whether the IL-6-neutralizing monoclonal antibody siltuximab, formerly CNTO 328, could enhance the activity of melphalan, and to examine some of the mechanisms underlying this interaction. Siltuximab increased the cytotoxicity of melphalan in KAS-6/1, INA-6, ANBL-6, and RPMI 8226 human myeloma cell lines (HMCLs) in an additive-to-synergistic manner, and sensitized resistant RPMI 8226.LR5 cells to melphalan. These anti-proliferative effects were accompanied by enhanced activation of drugspecific apoptosis in HMCLs grown in suspension, and in HMCLs co-cultured with a humanderived stromal cell line. Siltuximab with melphalan enhanced activation of caspase-8, caspase-9, and the downstream effector caspase- 3 compared with either of the single agents. This increased induction of cell death occurred in association with enhanced Bak activation. Neutralization of IL-6 also suppressed signalling through the phosphoinositide 3-kinase/Akt pathway, as evidenced by decreased phosphorylation of Akt, p70 S6 kinase and 4E-BP1. Importantly, the siltuximab/ melphalan regimen demonstrated enhanced anti-proliferative effects against primary plasma cells derived from patients with myeloma, monoclonal gammopathy of undetermined significance, and amyloidosis. These studies provide a rationale for translation of siltuximab into the clinic in combination with melphalan-based therapies.
\end{abstract}

(C) 2011 Blackwell Publishing Ltd

Correspondence: Dr Robert Z. Orlowski, The University of Texas M. D. Anderson Cancer Center, Department of Lymphoma \& Myeloma, 1515 Holcombe Blvd., Unit 429, Houston, TX 77030-4009, USA. rorlowsk@ mdanderson.org.

These data were presented in part at the 51st Annual Meeting and Exposition of the American Society of Hematology in New Orleans, LA, December 6, 2009.

Please note: Wiley-Blackwell are not responsible for the content or functionality of any supporting materials supplied by the authors. Any queries (other than missing material) should be directed to the corresponding author for the article. 


\section{Keywords}

Akt; Interleukin-6; melphalan; multiple myeloma; siltuximab

Therapeutic outcomes in patients with multiple myeloma have been steadily improving, due mainly to the advent of novel agents, including proteasome inhibitors, such as bortezomib (Shah \& Orlowski, 2009), and immunomodulatory drugs, such as thalidomide and lenalidomide (Dimopoulos et al, 2008). Initially approved in the relapsed and/or refractory setting (Laubach et al, 2009), these drugs have now been incorporated into induction and maintenance therapy (Palumbo \& Rajkumar, 2009), and have contributed to a doubling of overall survival in this disease. However, even the best combination strategies achieve complete remissions in less than half of patients, indicating an important role for primary drug resistance in promoting myeloma cell survival. Cytokines produced in the bone marrow microenvironment are likely to play an important role in mediating primary drug resistance. Myeloma is characterized by the accumulation of clonal plasma cells in the bone marrow, where they are protected by a microenvironment that promotes plasma cell survival and proliferation (Hideshima et al, 2007). Adhesion of myeloma cells to bone marrow stromal cells (BMSCs) induces the latter to secrete pro-survival cytokines, including interleukin (IL)-6 (Hideshima et al, 2007). IL-6 activates multiple cell survival and proliferation signalling pathways in myeloma cells, including the Janus kinase/signal transducer and activator of transcription 3 (JAK/STAT-3) pathway, the mitogen-activated protein kinase kinase/extracellular signal-related kinase (MEK/ERK) pathway, and the phosphoinositide 3kinase (PI3-K)/Akt pathway (Hideshima et al, 2007). Not only is IL-6 important for the pathogenesis of multiple myeloma, with increased IL-6 expression found in the bone marrow mononuclear cells of myeloma patients (Portier et al, 1991), but increased serum levels of IL-6 and soluble IL-6 receptor, an IL-6 agonist frequently found complexed to IL-6 in serum, are also indicators of poor prognosis for myeloma patients (Greipp et al, 1998; Stasi et al, 1998; Wierzbowska et al, 1999), suggesting that IL-6 may be a good therapeutic target for this disease.

Siltuximab, formerly CNTO 328, a chimeric human-mouse monoclonal IL-6 neutralizing antibody, has demonstrated promising anti-myeloma activity in combination with bortezomib (Voorhees et al, 2007) and dexamethasone (Voorhees et al, 2009) in preclinical myeloma models. As a result of the excellent rationale for IL-6 blockade in myeloma (Trikha et al, 2003), as well as these pre-clinical data, siltuximab is now being studied in clinical trials focusing initially on combinations with bortezomib (Rossi et al, 2008) and dexamethasone (Voorhees et al, 2009). Pre-clinically, siltuximab inhibited phosphorylation of ERK-1/2, STAT-1, and STAT-3 in human multiple myeloma cell lines (HMCLs) in the presence of IL-6, thus blocking critical signals for cell growth and survival (Voorhees et al, 2007). In addition, siltuximab inhibited the bortezomib-induced up-regulation of myeloid cell leukaemia-1 (Mcl-1) and heat shock protein 70 (HSP-70), both of which may be involved in inducible chemoresistance (Voorhees et al, 2007). Due to this promising preclinical activity shown by siltuximab, as well as other anti-IL-6 approaches, such as the single-chain fragment NRI (Yoshio-Hoshino et al, 2007) and the humanized antibody 1339 (Fulciniti et al, 2009), we sought to evaluate the effect of combining siltuximab with melphalan in HMCLs.

The bifunctional alkylating agent melphalan is widely used for the treatment of myeloma, with the formation of DNA interstrand crosslinks regarded as the critical toxic lesion (Spanswick et al, 2002; Sunters et al, 1992). Melphalan is administered both as high dose therapy (HDM) prior to autologous stem cell transplant (ASCT), and as low dose therapy in combination with prednisone and, more recently, prednisone plus thalidomide, lenalidomide, 
or bortezomib, in patients who are not candidates for ASCT (Hulin et al, 2009; Merchionne et al, 2007; Palumbo et al, 2009). While initial responses are good, virtually all patients relapse, often with refractory disease (Merchionne et al, 2007). HDM followed by ASCT causes an increase in IL-6 production during haematological recovery that may promote the survival of melphalan-resistant cells, suggesting that inhibition of IL-6 in combination with standard or high dose melphalan may improve clinical outcomes (Rossi et al, 2005).

Chemotherapy induces apoptosis through activation of the extrinsic (caspase-8) death receptor pathway, and/or the intrinsic (caspase-9) mitochondrial pathway, both of which lead to downstream activation of caspase-3. Unless the extrinsic pathway produces robust activation of caspase- 8 , both pathways require mitochondrial outer membrane permeabilization (MOMP) to commit the cell to apoptosis (Scaffidi et al, 1998; Sheridan \& Martin, 2008). Bak and Bax, two pro-apoptotic members of the Bcl-2 family of proteins, are activated by a conformational change that exposes an N-terminal epitope and promotes selfoligomerization in the mitochondrial outer membrane and induction of MOMP (Green \& Kroemer, 2004; Leber et al, 2007). Studies using Bak/Bax double knockout mice and mouse embryo fibroblasts have demonstrated that activation of at least one of these proteins is necessary for induction of apoptosis (Cheng et al, 2001; Lindsten et al, 2000; Willis et al, 2005). Anti-apoptotic Bcl-2 family proteins, such as Mcl-1, Bcl- $\mathrm{x}_{\mathrm{L}}$ and $\mathrm{Bcl}-2$, promote cell survival by inhibiting oligomerization of Bak and Bax, while the pro-apoptotic BH3-only proteins, including Bim, Bid, PUMA, Noxa and Bad, promote apoptosis by binding to and neutralizing the anti-apoptotic proteins, releasing Bak and Bax inhibition (Chipuk \& Green, 2008; Willis et al, 2005, 2007). While we have previously demonstrated that siltuximab decreased expression of anti-apoptotic Mcl-1 (Voorhees et al, 2007), a protein critical for the survival of myeloma cells (Derenne et al, 2002; Zhang et al, 2002), the effect of siltuximab and the siltuximab/melphalan combination on downstream Bak and Bax activation in HMCLs is unknown.

Here we demonstrate that the combination of siltuximab and melphalan attenuated cell proliferation in an additive to synergistic manner, and enhanced apoptosis in HMCLs. This increased cell death correlated with enhanced Bak activation, and siltuximab also inhibited IL-6 activation of the pro-survival PI3-K/Akt signalling pathway. Importantly, the siltuximab/melphalan combination was also effective in patient-derived myeloma samples, and partially overcame melphalan resistance. These results support translation of siltuximab into the clinic in combination with melphalan-based therapies.

\section{Materials and methods}

\section{Materials}

Siltuximab and the F105 isotype control antibody recognizing the human immunodeficiency virus type $1 \mathrm{gp} 120$ envelope protein were provided by Centocor Ortho Biotech, Inc. (Horsham, PA, USA), and diluted in $0.15 \mathrm{~mol} / \mathrm{l}$ sodium chloride and $0.01 \mathrm{~mol} / \mathrm{l}$ sodium phosphate (pH 7.2). Melphalan, from Sigma-Aldrich (St. Louis, MO, USA), was dissolved

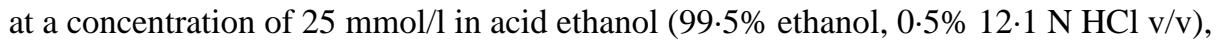
diluted to a $5 \mathrm{mmol} / \mathrm{l}$ stock in acid saline $(0 \cdot 15 \mathrm{~mol} / \mathrm{l} \mathrm{NaCl}, 0 \cdot 01 \mathrm{~N} \mathrm{HCl})$, and further dilutions were in $20 \%$ acid ethanol $/ 80 \%$ acid saline.

\section{Cell lines and patient myeloma samples}

The IL-6 dependent HMCLs KAS-6/1, INA-6, and ANBL-6 were provided by Dr. Diane Jelinek (Mayo Clinic, Rochester, MN, USA), Dr. Martin Gramatzki (University of Erlangen-Nurnberg, Germany), and Dr. Beverly S. Mitchell (Stanford University, Palo Alto, CA, USA), respectively. HS5-GFP human stromal cells, and RPMI 8226.LR5 melphalan- 
resistant myeloma cells (Bellamy et al, 1991), were provided by Dr. William Dalton (H. Lee Moffitt Cancer Center, Tampa, FL, USA), while RPMI 8226 cells were from the American Type Culture Collection (Manassas, VA, USA). These cell lines were validated through The M. D. Anderson Cancer Center Characterized Cell Line Core Facility. KAS-6/1, INA-6, ANBL-6, and RPMI 8226 cells, and human stromal cells expressing green fluorescent protein (HS5-GFP), were propagated in culture as described previously (Voorhees et al, 2007, 2009). RPMI 8226.LR5 cells were grown in the presence of $5 \mu \mathrm{mol} / \mathrm{l}$ melphalan, which was removed for at least 1 week prior to the indicated experiments. Media was supplemented with $1 \mathrm{ng} / \mathrm{ml}$ human recombinant IL-6 from R\&D Systems (Minneapolis, MN) for IL-6-dependent cells, except when HMCLs were grown in the presence of stromal cells. Primary plasma cells were purified from patient bone marrow aspirates collected under a protocol approved by the Institutional Review Board of The University of Texas M. D. Anderson Cancer Center after informed consent was obtained in compliance with the Declaration of Helsinki. Mononuclear cells were isolated using density gradient centrifugation with Ficoll-Paque ${ }^{\mathrm{TM}}$ Plus from GE Healthcare Life Sciences (Piscataway, NJ, USA), followed by immunomagnetic separation using a RoboSep ${ }^{\circledR}$ machine and EasySep ${ }^{\circledR}$ anti-CD138 magnetic beads from STEMCELL Technologies, Inc. (Vancouver, BC, USA).

\section{Cell viability assays}

Cell viability was measured using the WST-1 reagent from Roche Applied Science (Indianapolis, IN, USA) as previously described (Kuhn et al, 2007, 2009). Data were calculated as a percent viability relative to the vehicle- or control antibody-treated cells, while mean inhibitory concentrations $\left(\mathrm{IC}_{50}\right.$ values) were calculated with GraphPad Prism from GraphPad Software (La Jolla, CA, USA) using non-linear regression.

\section{Apoptosis assays}

INA-6 and KAS-6/1 cells grown in suspension were treated as described in the text, and when co-cultures were established, myeloma cells were plated onto HS5-GFP stromal cells that had been allowed to attach overnight before treatment. Programmed cell death was evaluated by staining with fluorescein isothiocyanate (FITC)-conjugated Annexin-V from BioVision, Inc. (Mountain View, CA, USA), followed by flow cytometry according to the manufacturer's protocol. In experiments where HS5-GFP cells were included, phycoerythrin (PE)-conjugated Annexin V was used instead. The DNA-binding dye TO-PRO-3 was used to distinguish cells with intact membranes from those with compromised membranes. Data were collected from 10000 events on a FACSCaliber machine using CellQuest software from Becton Dickinson (Franklin Lakes, NJ, USA), and analysed using FlowJo software from Tree Star, Inc. (Ashland, OR, USA).

Caspase activity assays were performed using CASPGLOW Active Caspase Staining Kits (BioVision, Inc.). Cells were incubated with irreversible fluorescent caspase inhibitors that specifically bind active caspases, and analysed by flow cytometry following the manufacturer's protocol.

\section{Western blotting}

Cells were lysed in radioimmunoprecipitation assay buffer $(1 \times$ phosphate-buffered saline, $1 \%$ Igepal, $0.1 \%$ sodium dodecyl sulphate, and $0.5 \%$ deoxycholate) supplemented with SIGMAFAST TM Protease Inhibitor Tablets and Phosphatase Inhibitor Cocktails I and II (Sigma-Aldrich). Proteins were separated by electrophoresis through NuPAGE ${ }^{\circledR}$ precast gels from Invitrogen (Carlsbad, CA, USA), and bands were visualized using either ECL ${ }^{\mathrm{TM}}$ (GE Healthcare Life Sciences) or Supersignal West Dura Extended Duration Substrate from Thermo Scientific (Rockford, IL, USA). Antibodies used included anti-Akt and -phospho- 
Akt, -Bid, -p70 S6 kinase and -phospho-p70 S6K, -4E-BP1 and -phospho-4E-BP1, from

Cell Signalling Technology, Inc. (Danvers, MA, USA), and anti- $\beta$-actin (Sigma-Aldrich).

\section{Bak and Bax activation assays}

Bak and Bax activation were evaluated by flow cytometry. Treated cells were fixed in $2 \%$ paraformaldehyde and resuspended in permeabilization buffer $(1 \times$ phosphate-buffered saline, $0.5 \%$ bovine serum albumin, and $0.3 \%$ saponin) containing $2 \mu \mathrm{g} / \mathrm{ml}$ anti-Bak Ab-1 antibody from CalBiochem/EMD4 Biosciences (Madison, WI, USA), $20 \mu \mathrm{g} / \mathrm{ml}$ anti-Bax 6A7 antibody (Sigma-Aldrich), or a control mouse IgG. Cells were then incubated with antimouse Alexa Fluor ${ }^{\circledR} 488$ conjugated secondary antibody (Invitrogen) prior to flow cytometry. Bak activation was calculated relative to the IgG control, while Bax activation was calculated relative to Bax staining of the untreated control cells.

Immunoprecipitation was also performed to evaluate Bak and Bax activation using a modification of the method described by Pei et al (Pei et al, 2007). Briefly, frozen cell pellets were lysed in CHAPS buffer (10 mmol/l HEPES, pH 7.4, $150 \mathrm{mmol} / \mathrm{l} \mathrm{NaCl}, 1 \%$ CHAPS and $1 \times$ SIGMAFAST ${ }^{\mathrm{TM}}$ Protease Inhibitor Tablets), DNA was sheered, and samples were clarified to remove insoluble material. Extracts were pre-cleared with protein $\mathrm{A} / \mathrm{G}$ agarose, and then incubated with anti-Bak $(1 \mu \mathrm{g})$ or anti-Bax $(2 \mu \mathrm{g})$ antibody overnight. Protein A/G agarose was added for an additional four hours and, after washing, the agarose-bound proteins were dissociated by boiling in sample buffer under denaturing and reducing conditions. The contents of the precipitates were then separated and analysed by Western blotting as described above.

\section{Statistical analyses}

Calcusyn software from Biosoft (Ferguson, MO, USA) was used to calculate combination indices (CIs) for the siltuximab/melphalan combinations using isobologram analysis, with CIs of $\$ 0 \cdot 9$ considered moderately synergistic, $<0 \cdot 7$ considered synergistic, and $<0 \cdot 1$ considered very strongly synergistic.

\section{Results}

\section{Siltuximab enhances melphalan cytotoxicity}

The impact of blocking IL-6 signalling on HMCLs was evaluated in IL-6-dependent KAS-6/1, INA-6 and ANBL-6 cells, which were exposed to clinically relevant concentrations of siltuximab, a neutralizing monoclonal antibody specific for human IL-6. INA-6 cells were the most sensitive to a 72-h exposure to siltuximab, with KAS-6/1 cells showing an intermediate sensitivity, and ANBL-6 cells demonstrating the highest $\mathrm{IC}_{50}$ (Fig 1A and Table SI). Also, INA-6 cells exhibited a more rapid response to siltuximab than KAS-6/1 or ANBL- 6 cells, in that the majority of the reduction in viability seen by $72 \mathrm{~h}$ was also visible after only $2 \mathrm{~d}$ (Table SI). Treatment of these cell lines with single-agent melphalan showed a narrower range of $\mathrm{IC}_{50}$ values, varying from 2.9 to $9.4 \mu \mathrm{mol} / 1$ at $48 \mathrm{~h}$ (Table SI). In all three of the cell lines, a 24-h pretreatment with siltuximab, followed by a 48-h treatment with melphalan, enhanced toxicity over either drug alone (Fig 1B-D). For example, in KAS-6/1 cells, siltuximab alone induced a $30 \%$ decrease in viability, melphalan at $4 \mu \mathrm{mol} / 1$ led to a $52 \%$ decrease in viability, while the combination resulted in an $83 \%$ decrease (Fig 1B). Similarly, siltuximab led to a $30 \%$ decrease in viability of INA-6 cells, melphalan at $1 \mu \mathrm{mol} / 1$ induced a $30 \%$ decrease, while the combination produced a $69 \%$ decrease in viability (Fig 1C).

Isobologram analysis was performed to evaluate the possibility that the siltuximab/ melphalan combination was synergistic. KAS-6/1 cells were treated with escalating anti- 
body doses and melphalan at a fixed 1:1 ratio based on the $\mathrm{IC}_{50}$ values of siltuximab at $72 \mathrm{~h}$ and melphalan at $48 \mathrm{~h}$. Cells were pretreated for $24 \mathrm{~h}$ with siltuximab concentrations ranging from 0.5 to $2 \cdot 0 \times$ the $\mathrm{IC}_{50}$, followed by addition of melphalan at the same ratios. The combination was synergistic at all doses tested, with CIs ranging from 0.253 to 0.487 (Table I). Because the order of drug administration can affect the outcome of combination chemotherapy, we investigated the effect of the sequence of addition using the siltuximab/ melphalan regimen. KAS-6/1 cells were either pretreated with antibody for $24 \mathrm{~h}$ followed by incubation with melphalan for $48 \mathrm{~h}$, simultaneously treated with both siltuximab and melphalan for $48 \mathrm{~h}$, or pretreated with melphalan for $8 \mathrm{~h}$ followed by incubation with siltuximab for $40 \mathrm{~h}$. While the siltuximab/melphalan combination was synergistic in all cases (Table SII), the synergy was strongest with siltuximab pretreatment, and weakest with melphalan pretreatment. Although experiments with fixed siltuximab:melphalan ratios were not performed in INA-6 and ANBL-6 cells, analysis of a smaller range of concentrations demonstrated that the combination was synergistic in INA- 6 cells, and at least additive when melphalan concentrations $\geq 7 \cdot 5 \mu \mathrm{mol} / \mathrm{l}$ were used in ANBL-6 cells (Table SIII).

The siltuximab/melphalan combination was next evaluated in IL-6 independent RPMI 8226 cells, and in their melphalan-resistant counterparts, RPMI 8226.LR5. As expected, RPMI 8226 cells were less sensitive to siltuximab than the IL-6 dependent HMCLs, but still suffered a $20-25 \%$ decrease in cell viability at siltuximab concentrations up to $15 \mu \mathrm{g} / \mathrm{ml}$ (Fig - S1A). When the combination of siltuximab and melphalan was evaluated, siltuximab enhanced the toxicity of melphalan in RPMI 8226 cells (Fig S1B,C). Isobologram analysis, performed over a range of drug concentrations, demonstrated synergistic interactions, with CIs ranging from 0.719 down to 0.368 (Table SVI). Siltuximab alone had a minimal effect on RPMI 8226.LR5 cells (Fig S1A), but when the combination was studied, IL-6 blockade potentiated the cytotoxic effects of melphalan (Fig S1B,C). Combination indices ranged from 0.911 to 0.675 (Table SVI), indicating the presence of moderate synergy, and supporting the possibility that siltuximab could partially overcome melphalan resistance.

\section{Role of apoptosis in the enhanced cytotoxicity of the siltuximab/melphalan combination}

To evaluate the contribution of apoptosis to the cytotoxic effect of the siltuximab/melphalan combination, cell surface Annexin V staining was analysed by flow cytometry. Siltuximab alone induced some apoptosis in KAS-6/1 and INA-6 cells (Fig 2A,B), and when siltuximab was combined with melphalan, apoptosis was significantly enhanced over either drug alone. In KAS-6/1 cells, siltuximab and melphalan as single agents resulted in $34.8 \%$ and $51.6 \%$ apoptosis respectively, while the combination resulted in $74.5 \%$ apoptotic cells (Fig $2 \mathrm{~A}$, lower panel). Similarly, in INA-6 cells, siltuximab and melphalan alone resulted in $26.8 \%$ and $42.6 \%$ apoptotic cells respectively, while the combination induced apoptosis in $67.1 \%$ of cells (Fig 2B, lower panel).

Induction of apoptosis with the siltuximab/melphalan combination was then evaluated by measuring the activation status of caspase-3, the common effector of programmed cell death. Both siltuximab and melphalan activated caspase- 3 as single agents, and this was significantly enhanced in KAS-6/1 and INA- 6 cells when the drugs were combined (Fig 3A,B, upper panels). As caspase-3 can be activated either through the intrinsic, caspase-9mediated arm of apoptosis, or through the extrinsic, caspase-8-mediated apoptotic pathway, the activation status of these caspases was determined as well. Notably, while siltuximab and melphalan activated caspase-8 (Fig 3A,B, middle panels) and caspase-9 (Fig 3A,B, lower panels) as single agents, the combination regimen demonstrated enhanced activation of both the intrinsic and extrinsic apoptotic pathways. 


\section{Siltuximab/melphalan overcomes the protective effect of stromal cells}

In order to more closely mimic the bone marrow microenvironment, HMCLs were cultured in the presence of the stromal cell line HS5-GFP. Stromal cells, with their ability to elaborate a number of cytokines that promote plasma cell proliferation and survival, had a protective effect on KAS-6/1 cells treated with single-agent siltuximab (Fig 4A, upper panel). With HS5-GFP cells present, only $11 \%$ of KAS-6/1 cells treated with siltuximab at $10 \mu \mathrm{g} / \mathrm{ml}$ stained positive for Annexin V, compared to $42 \%$ of KAS-6/1 cells grown in the absence of stromal cells. A slight trend for a protective effect was also seen in the INA-6 model (Fig 4B, upper panel), though this did not reach statistical significance. When both cell lines were exposed to siltuximab/melphalan, however, blockade of IL-6 signalling was successful at enhancing apoptosis at the majority of melphalan concentrations tested (Fig 4A,B, lower panels).

\section{Bak and Bax activation are associated with the response to siltuximab/melphalan}

Type I programmed cell death is often associated with activation of pro-apoptotic Bcl-2 family members such as Bak and Bax, and this possibility was evaluated in KAS-6/1 cells by flow cytometry with active conformation-specific antibodies. Siltuximab alone induced substantial dose-dependent Bak activation (Fig 5A, left panel), and also statistically significant increases in Bax activation (Fig 5A, right panel), though the latter occurred in a minority of the cell population. When KAS-6/1 cells were pretreated with siltuximab followed by melphalan, Bak activation was significantly potentiated over that achieved with either drug alone (Fig 5B, left panel). While melphalan treatment alone showed a small, dose-dependent activation of Bax in KAS-6/1 cells, the siltuximab/melphalan regimen did not significantly increase this activation further (Fig 5B, right panel). In order to confirm these findings, immunoprecipitation experiments were performed in both KAS-6/1 (Fig 5C) and INA-6 cells (Fig 5D). Both melphalan and siltuximab activated Bak to some extent as single agents, but the level of active Bak was increased when the drugs were combined, supporting a role for this mechanism in the enhanced induction of apoptosis. In contrast, activated Bax was not consistently detected in either the KAS-6/1 or INA- 6 cells following treatment with siltuximab and melphalan (data not shown).

\section{Siltuximab-induced apoptosis is associated with the cleavage of Bid to its active form}

Because both siltuximab and melphalan activated caspase- 8 , we tested whether the caspase- 8 substrate Bid was cleaved to pro-apoptotic tBid following siltuximab and melphalan treatment. Cleavage of Bid to tBid was observed in INA- 6 cells treated for $72 \mathrm{~h}$ with siltuximab, but was not observed following melphalan treatment alone, and was not enhanced when the two drugs were combined (Fig 6A). To determine whether Bid cleavage was an early event in apoptosis, INA-6 cells treated with siltuximab were harvested from 8 to $32 \mathrm{~h}$, followed by Western blotting for Bid expression. tBid was present as early as $8 \mathrm{~h}$ following siltuximab treatment, and levels continued to increase through to $32 \mathrm{~h}$ as fulllength Bid levels decreased (Fig 6B). Siltuximab treatment also led to a decrease in Bid levels in KAS-6/1 cells (Fig S2A), suggesting cleavage of Bid to pro-apoptotic tBid. However, due to the difficulty of detecting tBid and the relatively low level of Bid in KAS-6/1 cells (Fig S2B), tBid was not detected.

\section{Suppression of Akt signalling by siltuximab}

Activity of the PI3K/Akt pathway has been implicated in plasma cell resistance to melphalan (Hamasaki et al, 2005; Hideshima et al, 2006), and it was therefore of interest to determine if siltuximab might be enhancing the effects of melphalan in part through this mechanism. Consistent with this possibility, single-agent siltuximab inhibited the activity of the Akt pathway, as judged by a decrease in the levels of phosphorylated, activated Akt in 
KAS-6/1 cells (Fig 6C). Also, in both KAS-6/1 (Fig 6C) and INA-6 cells (Fig 6D), the levels of two phosphorylated downstream targets of Akt, phospho-p70 S6 kinase and phospho-4E-BP1, were decreased by IL-6 blockade. Notably, siltuximab combined with 2 $\mu \mathrm{mol} / \mathrm{l}$ melphalan reduced the levels of p70 S6 kinase and 4E-BP1 to an even greater extent than was the case for either siltuximab alone or melphalan alone. Qualitatively similar results were obtained in ANBL-6 cells using siltuximab alone, although with less of an effect of the combination with melphalan (Fig S1C).

\section{Siltuximab and melphalan are active against primary plasma cells}

Blockade of IL-6 signalling in the clinical setting, either with the anti-receptor antibody tocilizumab (Nishimoto et al, 2005), or with the neutralizing antibody siltuximab and the proteasome inhibitor bortezomib (Rossi et al, 2008), have been shown to induce mild cytopenias. To examine the effects of siltuximab and melphalan on non-transformed cells, this combination was tested against peripheral blood mononuclear cells (PBMCs) isolated from two healthy donors. Siltuximab alone reduced cell viability by $12-20 \%$ (Fig S3A,B), and when melphalan was added, there was a further decrease compared to that induced with either drug alone. We then examined the activity of the siltuximab/melphalan combination against malignant primary cells by challenging $\mathrm{CD} 138^{+}$plasma cells isolated from the bone marrow aspirates of three patients with multiple myeloma (Fig 7A), one patient with amyloidosis (Fig 7B), and one patient with monoclonal gammopathy of undetermined significance (MGUS; Fig 7C). In cells isolated from the three myeloma patients, reductions in cell viability following single-agent siltuximab treatment ranged from 28 to $43 \%$ (Fig 7A), which were comparable to those we have previously reported after IL-6 blockade in primary samples (Voorhees et al, 2007; Voorhees et al, 2009). Plasma cells from patient MM-62 with newly diagnosed disease (Fig 7A, left panel) suffered a statistically significant reduction in viability with siltuximab and melphalan at all concentrations of the alkylating agent that were tested. Patients MM-50 (Fig 7A, middle panel) and MM-52 (Fig 7A, right panel) both had received multiple prior lines of therapy, including melphalan-based regimens from which their diseases had relapsed. Their plasma cells were less sensitive to the siltuximab/melphalan combination, but with melphalan at $2.5 \mu \mathrm{mol} / \mathrm{l}$, both showed enhanced activity of the regimen compared to melphalan alone. We also had the opportunity to study CD138 ${ }^{+}$plasma cells isolated from a patient with newly diagnosed systemic amyloidosis (Fig 7B). Siltuximab alone reduced cell viability by $24 \%$ in $72 \mathrm{~h}$, and when melphalan was added for $48 \mathrm{~h}$, cell viability was significantly reduced compared to either drug alone. Similarly, plasma cells isolated from a patient with MGUS were more sensitive to the combination. Purified CD $138^{+}$cells showed a $40 \%$ reduction in viability with siltuximab and $5 \mu \mathrm{mol} / \mathrm{l}$ melphalan, compared with only $8 \%$ for siltuximab alone and $11 \%$ for melphalan alone (Fig 7C). Notably, these reductions in the viability of transformed cells were more robust than was the case for the PBMC samples, supporting the possibility of a therapeutic index. When the two latter samples were compared to the three primary isolates (MM-62, MM-50 and Amyloidosis-59) for which there was data combining siltuximab with $7.5 \mu \mathrm{mol} / \mathrm{l}$ melphalan, the plasma cell dyscrasia-derived cells showed a mean residual viability of $34 \%$, compared to $65 \%$ for the PBMCs (Fig S3C), though due to the small sample size, this trend did not reach statistical significance $(P=0 \cdot 1125)$. To further evaluate the selectivity of this therapeutic regimen, HS5-GFP stromal cells were pretreated with siltuximab for $24 \mathrm{~h}$, followed by $48 \mathrm{~h}$ of treatment with melphalan. Blockade of IL-6 signalling alone did not impact on stromal cell viability (Fig 7D), while melphalan alone did induce a dose-dependent reduction in viability (Fig 7D). When siltuximab was added to melphalan, no enhanced reduction of viability was seen at lower melphalan concentrations, though a modest enhancement was seen at the highest melphalan concentration tested. 


\section{Discussion}

In the bone marrow microenvironment, IL-6 activates multiple cell signalling pathways that promote myeloma cell proliferation, survival and resistance to chemotherapy. Inhibition of IL-6 with the clinical grade antibody siltuximab enhanced melphalan toxicity in IL-6dependent and -independent HMCLs, in melphalan-resistant RPMI 8226.LR5 cells, and in $\mathrm{CD} 138^{+}$plasma cells isolated from several patients diagnosed with plasma cell dyscrasias. Siltuximab also inhibited signalling through the PI3-K/Akt pathway as evidenced by reduced Akt, p70 S6 kinase and 4E-BP1 phosphorylation following antibody treatment. This pathway may be important for drug resistance, because activation of the PI3-K/Akt pathway in myeloma cells by IL- 6 has been reported to confer resistance to dexamethasone-mediated apoptosis (Hideshima et al, 2001). Multiple mechanisms have been reported for inhibition of apoptosis by Akt, including phosphorylation and inactivation of the pro-apoptotic protein Bad (Datta et al, 1997); phosphorylation and inactivation of the FoxO forkhead transcription factor responsible for upregulation of pro-apoptotic Bim in response to growth factor withdrawal (Downward, 2004); and inhibition of Bak and Bax activation following Bid cleavage via a mechanism that promotes association of hexokinases with the mitochondrial membrane (Majewski et al, 2004). The PI3-K/mTOR inhibitor NVP-BEZ235 (Baumann et al, 2009) and the Akt inhibitor perifosine (Hideshima et al, 2006) both enhance the cytotoxicity of melphalan in HMCLs, suggesting that the PI3-K/Akt pathway is also involved in melphalan resistance. As such, downregulation of Akt activation could be an important mechanism of enhanced cytotoxicity when siltuximab and melphalan are combined, though other mechanisms of melphalan resistance, such as through the Fanconi anaemia/BRCA pathway, would not be impacted (Chen et al, 2005). Akt phosphorylation was not detected in INA-6 cells grown in the presence of IL-6, either because IL-6 does not induce Akt phosphorylation in INA-6 cells, or phosphorylated Akt levels were too low to be detected by Western blot. To rule out the possibility that Akt phosphorylation was transient in INA- 6 cells and therefore could not be detected $8 \mathrm{~h}$ after addition of media with fresh IL-6, cells were IL-6 starved for 4-16 h followed by addition of IL-6. Under these conditions, Akt phosphorylation was induced within $30 \mathrm{~min}$ in KAS-6/1 and ANBL-6 cells, but not in INA-6 cells (data not shown). Akt activation leads to activation of the downstream mTOR/Raptor complex, which in turn phosphorylates p70 S6 kinase and 4E-BP1, leading to activation of cap-dependent translation (Kroczynska et al, 2009). The inhibition of p70 S6 kinase and 4E-BP1 phosphorylation by siltuximab in INA-6 cells demonstrates that an IL-6dependent pathway is mediating mTOR/Raptor activity in these cells, and suggests the possibility that the Akt phosphorylation was below detectable levels.

Although the activity of siltuximab in combination with bortezomib in HMCLs correlated with its ability to downregulate $\mathrm{Mcl}-1_{\mathrm{L}}$ expression (Voorhees et al, 2007), that did not appear to be the case with the siltuximab/melphalan combination. While siltuximab downregulated Mcl- $1_{\mathrm{L}}$ in both INA- 6 and ANBL- 6 cells, it had little effect on Mcl- $1_{\mathrm{L}}$ expression in KAS-6/1 cells (data not shown). Notably, however, siltuximab and melphalan were able to interact in a synergistic fashion in HMCL models that expressed mutant, nonfunctional forms of p53 (ANBL-6 and INA-6 cells; (Stuhmer et al, 2005)), temperaturesensitive forms of p53 (RPMI 8226 cells; (Teoh et al, 2000)), or in which wild-type p53 expression has been found to be suppressed (KAS-6/1; (Hodge et al, 2005)). Enhanced apoptosis with the siltuximab/melphalan combination seemed to depend on the ability of siltuximab to activate the mitochondrial-dependent apoptotic pathway at least in part through activation of caspase- 8 followed by cleavage of Bid to tBid and activation of Bak. Melphalan-induced caspase- 8 activation, however, did not lead to Bid cleavage, indicating that Bak activation in response to melphalan was mediated by a different Bcl-2 family protein(s). The relatively weak activation of Bax in comparison to Bak by both siltuximab and melphalan may reflect a low level of Bax expression in these cells and is likely to be 
cell line specific, as Bax activation in response to melphalan has been previously reported in an HMCL (Gomez-Bougie et al, 2005).

While the sample size was small, the three patients (one myeloma, one amyloidosis, and one MGUS) who had no prior therapy, showed a statistically significant effect of the combination over either drug alone $(P<0.05)$, whereas in the two myeloma patients who had received prior melphalan therapy (MM-50 and MM-52), siltuximab plus melphalan was significantly more effective than melphalan alone at some doses, but was not significantly more effective than siltuximab alone. In the clinical setting, siltuximab would probably be added to melphalan-based therapies that include other drugs, such as melphalan/ dexamethasone or bortezomib/melphalan/prednisone, and it would be interesting to determine the effectiveness of siltuximab on patient-derived $\mathrm{CD} 138^{+}$cells with these drug combinations.

Siltuximab specifically neutralizes only human IL-6, precluding studies of this targeted agent in standard systemic murine in vivo model systems. Moreover, study of this agent in models incorporating human fetal tissue is barred, obviating the use of techniques that provide a human microenvironment by implanting a fetal bone chip into the flanks of immunodeficient mice (Tassone et al, 2005). However, IL-6 levels rise dramatically in the peri-transplant setting in myeloma patients receiving high dose melphalan therapy (Condomines et al, 2010; Rossi et al, 2005), suggesting that blockade of IL-6 in this setting could be of interest. Indeed, results from clinical trials combining BE-8, a murine mAb against IL-6, with dexamethasone and high dose melphalan followed by ASCT in myeloma patients, do indicate that inhibition of IL-6 is clinically beneficial in combination with HDM regimens. The first study, involving 16 patients with relapsed myeloma, had a complete remission rate of $37.5 \%$, and an overall response rate of $81.3 \%$, with no significant added toxicity of BE-8, and overall survival was $68.1 \%$ at 16 months (Moreau et al, 2000). In the second study, BE-8 was administered 1 day prior to dexamethasone, and was given daily until haematological recovery following ASCT. In 24 newly diagnosed myeloma patients, there was a complete remission rate of $16.7 \%$, a very good partial response rate of $37.5 \%$ and a partial response rate of $25 \%$, with reduced toxicity compared to HDM alone (Rossi et al, 2005). Overall survival was $68.2 \%$ at 5 years, and median event-free survival was 35 months (Rossi et al, 2005). Several patients had extremely high IL-6 levels beginning 6-8 d following ASCT, and BE-8 was unable to reach a high enough concentration to effectively inhibit IL-6 in these patients due to the short, 3-4 d half-life of this antibody (Rossi et al, 2005). The authors suggested that an anti-IL-6 antibody, such as siltuximab, with a longer half-life of 17-18 d (Puchalski et al, 2010), may be able to achieve a higher circulating concentration. In a recent phase I/II study in patients with progressive metastatic renal cell carcinoma, siltuximab administered at $6 \mathrm{mg} / \mathrm{kg}$ every 2 weeks achieved a peak serum concentration above $100 \mu \mathrm{g} / \mathrm{ml}$ directly following administration, and maintained a concentration above $21 \mu \mathrm{g} / \mathrm{ml}$ throughout the course of the study (Puchalski et al, 2010). Following this regimen, siltuximab was able to suppress serum C-reactive protein (CRP, a marker of IL-6 activity) in renal cell carcinoma patients when CRP was $\$ 30 \mathrm{mg} / \mathrm{l}$ prior to treatment (Puchalski et al, 2010).

These findings together support the evaluation of siltuximab in the clinic in combination with melphalan-based therapies, including either high dose therapy in transplant-eligible patients, or standard dose melphalan-containing induction regimens in transplant-ineligible patients, such as with the combination of bortezomib, melphalan, and prednisone (VMP). Indeed, a randomized trial is currently underway comparing the activity of VMP to that of siltuximab with VMP (NCT00911859). Data from this study will be helpful in determining the clinical benefit of IL-6 blockade as part of therapy for newly diagnosed multiple 
myeloma, and in further validating the hypothesis that siltuximab enhances the clinical activity of melphalan.

\section{Supplementary Material}

Refer to Web version on PubMed Central for supplementary material.

\section{Acknowledgments}

The authors would like to acknowledge the staff at the Flow Cytometry Core Facility at UNC (supported by NIH grant P30 CA16086), and the Flow Cytometry and Cellular Imaging Core Facility and the Characterized Cell Line Core Facility at M. D. Anderson (supported by NCI grant P30 CA16672). R.Z.O., a Leukemia \& Lymphoma Society Scholar in Clinical Research, would like to acknowledge support from the Leukemia \& Lymphoma Society (6096-07), and the National Cancer Institute (R01 CA102278 and P50 CA142509).

\section{References}

Baumann P, Mandl-Weber S, Oduncu F, Schmidmaier R. The novel orally bioavailable inhibitor of phosphoinositol-3-kinase and mammalian target of rapamycin, NVP-BEZ235, inhibits growth and proliferation in multiple myeloma. Experimental Cell Research. 2009; 315:485-497. [PubMed: 19071109]

Bellamy WT, Dalton WS, Gleason MC, Grogan TM, Trent JM. Development and characterization of a melphalan-resistant human multiple myeloma cell line. Cancer Research. 1991; 51:995-1002. [PubMed: 1988143]

Chen Q, Van der Sluis PC, Boulware D, Hazlehurst LA, Dalton WS. The FA/BRCA pathway is involved in melphalan-induced DNA interstrand cross-link repair and accounts for melphalan resistance in multiple myeloma cells. Blood. 2005; 106:698-705. [PubMed: 15802532]

Cheng EH, Wei MC, Weiler S, Flavell RA, Mak TW, Lindsten T, Korsmeyer SJ. BCL-2, BCL-X(L) sequester BH3 domain-only molecules preventing BAX- and BAK-mediated mitochondrial apoptosis. Molecular Cell. 2001; 8:705-711. [PubMed: 11583631]

Chipuk JE, Green DR. How do BCL-2 proteins induce mitochondrial outer membrane permeabilization? Trends in Cell Biology. 2008; 18:157-164. [PubMed: 18314333]

Condomines M, Veyrune JL, Larroque M, Quittet P, Latry P, Lugagne C, Hertogh C, Kanouni T, Rossi JF, Klein B. Increased plasma-immune cytokines throughout the high-dose melphalaninduced lymphodepletion in patients with multiple myeloma: a window for adoptive immunotherapy. Journal of Immunology. 2010; 184:1079-1084.

Datta SR, Dudek H, Tao X, Masters S, Fu H, Gotoh Y, Greenberg ME. Akt phosphorylation of BAD couples survival signals to the cell-intrinsic death machinery. Cell. 1997; 91:231-241. [PubMed: 9346240]

Derenne S, Monia B, Dean NM, Taylor JK, Rapp MJ, Harousseau JL, Bataille R, Amiot M. Antisense strategy shows that $\mathrm{Mcl}-1$ rather than $\mathrm{Bcl}-2$ or $\mathrm{Bcl}-\mathrm{x}(\mathrm{L})$ is an essential survival protein of human myeloma cells. Blood. 2002; 100:194-199. [PubMed: 12070027]

Dimopoulos MA, Kastritis E, Rajkumar SV. Treatment of plasma cell dyscrasias with lenalidomide. Leukemia. 2008; 22:1343-1353. [PubMed: 18509355]

Downward J. PI 3-kinase, Akt and cell survival. Seminars in Cell \& Developmental Biology. 2004; 15:177-182. [PubMed: 15209377]

Fulciniti M, Hideshima T, Vermot-Desroches C, Pozzi S, Nanjappa P, Shen Z, Patel N, Smith ES, Wang W, Prabhala R, Tai YT, Tassone P, Anderson KC, Munshi NC. A high-affinity fully human anti-IL-6 mAb, 1339, for the treatment of multiple myeloma. Clinical Cancer Research. 2009; 15:7144-7152. [PubMed: 19934301]

Gomez-Bougie P, Oliver L, Le Gouill S, Bataille R, Amiot M. Melphalan-induced apoptosis in multiple myeloma cells is associated with a cleavage of Mcl-1 and Bim and a decrease in the Mcl-1/Bim complex. Oncogene. 2005; 24:8076-8079. [PubMed: 16091744]

Green DR, Kroemer G. The pathophysiology of mitochondrial cell death. Science. 2004; 305:626-629. [PubMed: 15286356] 
Greipp PR, Leong T, Bennett JM, Gaillard JP, Klein B, Stewart JA, Oken MM, Kay NE, Van Ness B, Kyle RA. Plasmablastic morphology - an independent prognostic factor with clinical and laboratory correlates: Eastern Cooperative Oncology Group (ECOG) myeloma trial E9486 report by the ECOG Myeloma Laboratory Group. Blood. 1998; 91:2501-2507. [PubMed: 9516151]

Hamasaki M, Hideshima T, Tassone P, Neri P, Ishitsuka K, Yasui H, Shiraishi N, Raje N, Kumar S, Picker DH, Jacob GS, Richardson PG, Munshi NC, Anderson KC. Azaspirane (N-N-diethyl-8,8dipropyl-2-azaspiro [4.5] decane-2-propanamine) inhibits human multiple myeloma cell growth in the bone marrow milieu in vitro and in vivo. Blood. 2005; 105:4470-4476. [PubMed: 15705788]

Hideshima T, Nakamura N, Chauhan D, Anderson KC. Biologic sequelae of interleukin-6 induced PI3-K/Akt signaling in multiple myeloma. Oncogene. 2001; 20:5991-6000. [PubMed: 11593406]

Hideshima T, Catley L, Yasui H, Ishitsuka K, Raje N, Mitsiades C, Podar K, Munshi NC, Chauhan D, Richardson PG, Anderson KC. Perifosine, an oral bioactive novel alkylphospholipid, inhibits Akt and induces in vitro and in vivo cytotoxicity in human multiple myeloma cells. Blood. 2006; 107:4053-4062. [PubMed: 16418332]

Hideshima T, Mitsiades C, Tonon G, Richardson PG, Anderson KC. Understanding multiple myeloma pathogenesis in the bone marrow to identify new therapeutic targets. Nature Reviews Cancer. 2007; 7:585-598.

Hodge DR, Peng B, Cherry JC, Hurt EM, Fox SD, Kelley JA, Munroe DJ, Farrar WL. Interleukin 6 supports the maintenance of $\mathrm{p} 53$ tumor suppressor gene promoter methylation. Cancer Research. 2005; 65:4673-4682. [PubMed: 15930285]

Hulin C, Facon T, Rodon P, Pegourie B, Benboubker L, Doyen C, Dib M, Guillerm G, Salles B, Eschard JP, Lenain P, Casassus P, Azais I, Decaux O, Garderet L, Mathiot C, Fontan J, Lafon I, Virion JM, Moreau P. Efficacy of melphalan and prednisone plus thalidomide in patients older than 75 years with newly diagnosed multiple myeloma: IFM 01/01 trial. Journal of Clinical Oncology. 2009; 27:3664-3670. [PubMed: 19451428]

Kroczynska B, Kaur S, Platanias LC. Growth suppressive cytokines and the AKT/mTOR pathway. Cytokine. 2009; 48:138-143. [PubMed: 19682919]

Kuhn DJ, Chen Q, Voorhees PM, Strader JS, Shenk KD, Sun CM, Demo SD, Bennett MK, van Leeuwen FW, Chanan-Khan AA, Orlowski RZ. Potent activity of carfilzomib, a novel, irreversible inhibitor of the ubiquitin-proteasome pathway, against preclinical models of multiple myeloma. Blood. 2007; 110:3281-3290. [PubMed: 17591945]

Kuhn DJ, Hunsucker SA, Chen Q, Voorhees PM, Orlowski M, Orlowski RZ. Targeted inhibition of the immunoproteasome is a potent strategy against models of multiple myeloma that overcomes resistance to conventional drugs and nonspecific proteasome inhibitors. Blood. 2009; 113:46674676. [PubMed: 19050304]

Laubach JP, Mahindra A, Mitsiades CS, Schlossman RL, Munshi NC, Ghobrial IM, Carreau N, Hideshima T, Anderson KC, Richardson PG. The use of novel agents in the treatment of relapsed and refractory multiple myeloma. Leukemia. 2009; 23:2222-2232. [PubMed: 19741729]

Leber B, Lin J, Andrews DW. Embedded together: the life and death consequences of interaction of the Bcl-2 family with membranes. Apoptosis. 2007; 12:897-911. [PubMed: 17453159]

Lindsten T, Ross AJ, King A, Zong WX, Rathmell JC, Shiels HA, Ulrich E, Waymire KG, Mahar P, Frauwirth K, Chen Y, Wei M, Eng VM, Adelman DM, Simon MC, Ma A, Golden JA, Evan G, Korsmeyer SJ, MacGregor GR, Thompson CB. The combined functions of proapoptotic Bcl-2 family members bak and bax are essential for normal development of multiple tissues. Molecular Cell. 2000; 6:1389-1399. [PubMed: 11163212]

Majewski N, Nogueira V, Robey RB, Hay N. Akt inhibits apoptosis downstream of BID cleavage via a glucose-dependent mechanism involving mitochondrial hexokinases. Molecular and Cellular Biology. 2004; 24:730-740. [PubMed: 14701745]

Merchionne F, Perosa F, Dammacco F. New therapies in multiple myeloma. Clinical and Experimental Medicine. 2007; 7:83-97. [PubMed: 17972050]

Moreau P, Harousseau JL, Wijdenes J, Morineau N, Milpied N, Bataille R. A combination of antiinterleukin 6 murine monoclonal antibody with dexamethasone and high-dose melphalan induces high complete response rates in advanced multiple myeloma. British Journal of Haematology. 2000; 109:661-664. [PubMed: 10886221] 
Nishimoto N, Kanakura Y, Aozasa K, Johkoh T, Nakamura M, Nakano S, Nakano N, Ikeda Y, Sasaki T, Nishioka K, Hara M, Taguchi H, Kimura Y, Kato Y, Asaoku H, Kumagai S, Kodama F, Nakahara H, Hagihara K, Yoshizaki K, Kishimoto T. Humanized anti-interleukin-6 receptor antibody treatment of multicentric Castleman disease. Blood. 2005; 106:2627-2632. [PubMed: 15998837]

Palumbo A, Rajkumar SV. Treatment of newly diagnosed myeloma. Leukemia. 2009; 23:449-456. [PubMed: 19005483]

Palumbo A, Dimopoulos MA, Delforge M, Kropff M, Foa R, Yu Z, Herbein L, Mei J, Jacques C, Catalano J. A phase III study to determine the efficacy and safety of lenalidomide in combination with melphalan and prednisone (MPR) in elderly patients with newly diagnosed multiple myeloma. Blood. 2009; 114 Abstract-613.

Pei XY, Dai Y, Tenorio S, Lu J, Harada H, Dent P, Grant S. MEK1/2 inhibitors potentiate UCN-01 lethality in human multiple myeloma cells through a Bim-dependent mechanism. Blood. 2007; 110:2092-2101. [PubMed: 17540843]

Portier M, Rajzbaum G, Zhang XG, Attal M, Rusalen C, Wijdenes J, Mannoni P, Maraninchi D, Piechaczyk M, Bataille R, Klein B. In vivo interleukin 6 gene expression in the tumoral environment in multiple myeloma. European Journal of Immunology. 1991; 21:1759-1762. [PubMed: 2060582]

Puchalski T, Prabhakar U, Jiao Q, Berns B, Davis HM. Pharmacokinetic and pharmacodynamic modeling of an anti-interleukin-6 chimeric monoclonal antibody (siltuximab) in patients with metastatic renal cell carcinoma. Clinical Cancer Research. 2010; 16:1652-1661. [PubMed: 20179212]

Rossi JF, Fegueux N, Lu ZY, Legouffe E, Exbrayat C, Bozonnat MC, Navarro R, Lopez E, Quittet P, Daures JP, Rouille V, Kanouni T, Widjenes J, Klein B. Optimizing the use of anti-interleukin-6 monoclonal antibody with dexamethasone and $140 \mathrm{mg} / \mathrm{m} 2$ of melphalan in multiple myeloma: results of a pilot study including biological aspects. Bone Marrow Transplantation. 2005; 36:771779. [PubMed: 16113665]

Rossi JF, Manges RF, Sutherland HJ, Jagannath S, Voorhees P, Sonneveld P, Delforge M, Pegourie B, Alegre A, de la Rubia J, La Police D, Bandekar R, Xie H, Orlowski RZ. Preliminary results of CNTO 328, an anti-interleukin-6 monoclonal antibody, in combination with bortezomib in the treatment of relapsed or refractory multiple myeloma. Blood. 2008; 112 Abstract-867.

Scaffidi C, Fulda S, Srinivasan A, Friesen C, Li F, Tomaselli KJ, Debatin KM, Krammer PH, Peter ME. Two CD95 (APO-1/Fas) signaling pathways. EMBO Journal. 1998; 17:1675-1687. [PubMed: 9501089]

Shah JJ, Orlowski RZ. Proteasome inhibitors in the treatment of multiple myeloma. Leukemia. 2009; 23:1964-1979. [PubMed: 19741722]

Sheridan C, Martin SJ. Commitment in apoptosis: slightly dead but mostly alive. Trends in Cell Biology. 2008; 18:353-357. [PubMed: 18603426]

Spanswick VJ, Craddock C, Sekhar M, Mahendra P, Shankaranarayana P, Hughes RG, Hochhauser D, Hartley JA. Repair of DNA interstrand crosslinks as a mechanism of clinical resistance to melphalan in multiple myeloma. Blood. 2002; 100:224-229. [PubMed: 12070031]

Stasi R, Brunetti M, Parma A, Di Giulio C, Terzoli E, Pagano A. The prognostic value of soluble interleukin-6 receptor in patients with multiple myeloma. Cancer. 1998; 82:1860-1866. [PubMed: 9587117]

Stuhmer T, Chatterjee M, Hildebrandt M, Herrmann P, Gollasch H, Gerecke C, Theurich S, Cigliano L, Manz RA, Daniel PT, Bommert K, Vassilev LT, Bargou RC. Nongenotoxic activation of the p53 pathway as a therapeutic strategy for multiple myeloma. Blood. 2005; 106:3609-3617. [PubMed: 16081689]

Sunters A, Springer CJ, Bagshawe KD, Souhami RL, Hartley JA. The cytotoxicity, DNA crosslinking ability and DNA sequence selectivity of the aniline mustards melphalan, chlorambucil and 4[bis(2-chloroethyl)amino] benzoic acid. Biochemical Pharmacology. 1992; 44:59-64. [PubMed: 1632839]

Tassone P, Neri P, Carrasco DR, Burger R, Goldmacher VS, Fram R, Munshi V, Shammas MA, Catley L, Jacob GS, Venuta S, Anderson KC, Munshi NC. A clinically relevant SCID-hu in vivo model of human multiple myeloma. Blood. 2005; 106:713-716. [PubMed: 15817674] 
Teoh G, Tai YT, Urashima M, Shirahama S, Matsuzaki M, Chauhan D, Treon SP, Raje N, Hideshima $\mathrm{T}$, Shima Y, Anderson KC. CD40 activation mediates p53-dependent cell cycle regulation in human multiple myeloma cell lines. Blood. 2000; 95:1039-1046. [PubMed: 10648420]

Trikha M, Corringham R, Klein B, Rossi JF. Targeted anti-interleukin-6 monoclonal antibody therapy for cancer: a review of the rationale and clinical evidence. Clinical Cancer Research. 2003; 9:4653-4665. [PubMed: 14581334]

Voorhees PM, Chen Q, Kuhn DJ, Small GW, Hunsucker SA, Strader JS, Corringham RE, Zaki MH, Nemeth JA, Orlowski RZ. Inhibition of interleukin-6 signaling with CNTO 328 enhances the activity of bortezomib in preclinical models of multiple myeloma. Clinical Cancer Research. 2007; 13:6469-6478. [PubMed: 17975159]

Voorhees PM, Chen Q, Small GW, Kuhn DJ, Hunsucker SA, Nemeth JA, Orlowski RZ. Targeted inhibition of interleukin-6 with CNTO 328 sensitizes pre-clinical models of multiple myeloma to dexamethasone-mediated cell death. British Journal of Haematology. 2009; 145:481-490. [PubMed: 19344406]

Wierzbowska A, Urbanska-Rys H, Robak T. Circulating IL-6-type cytokines and sIL-6R in patients with multiple myeloma. British Journal of Haematology. 1999; 105:412-419. [PubMed: 10233412]

Willis SN, Chen L, Dewson G, Wei A, Naik E, Fletcher JI, Adams JM, Huang DC. Proapoptotic Bak is sequestere by $\mathrm{Mcl}-1$ and $\mathrm{Bcl}-\mathrm{xL}$, but not $\mathrm{Bcl}-2$, until displaced by $\mathrm{BH} 3$-only proteins. Genes and Development. 2005; 19:1294-1305. [PubMed: 15901672]

Willis SN, Fletcher JI, Kaufmann T, van Delft MF, Chen L, Czabotar PE, Ierino H, Lee EF, Fairlie WD, Bouillet P, Strasser A, Kluck RM, Adams JM, Huang DC. Apoptosis initiated when BH3 ligands engage multiple Bcl-2 homologs, not Bax or Bak. Science. 2007; 315:856-859. [PubMed: 17289999]

Yoshio-Hoshino N, Adachi Y, Aoki C, Pereboev A, Curiel DT, Nishimoto N. Establishment of a new interleukin-6 (IL-6) receptor inhibitor applicable to the gene therapy for IL-6-dependent tumor. Cancer Research. 2007; 67:871-875. [PubMed: 17283116]

Zhang B, Gojo I, Fenton RG. Myeloid cell factor-1 is a critical survival factor for multiple myeloma. Blood. 2002; 99:1885-1893. [PubMed: 11877256] 

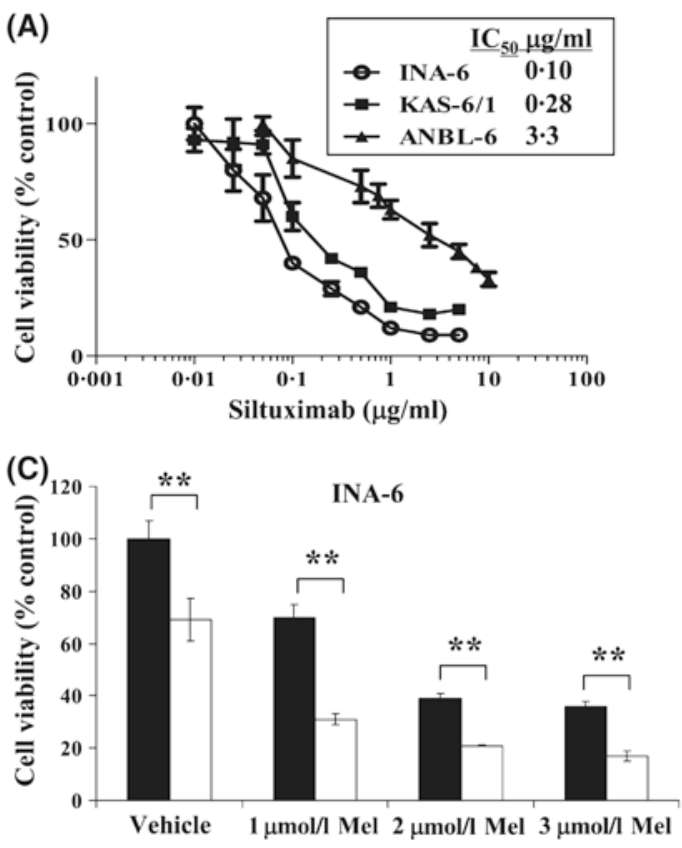

(B)



(D)

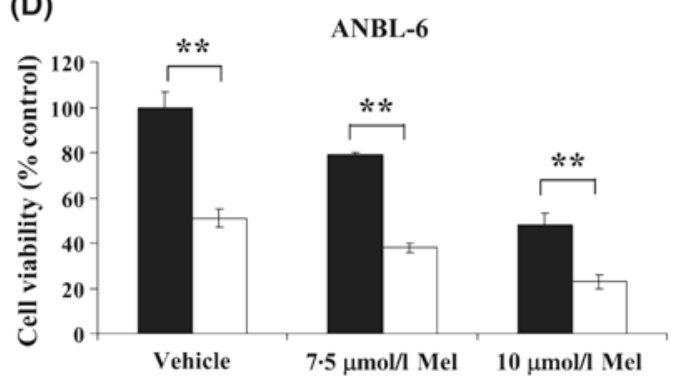

Fig 1.

Siltuximab enhances the anti-proliferative effects of melphalan. (A) The effect of IL-6 blockade alone was evaluated in IL-6-dependent HMCLs, which were seeded in 96-well plates. They were then treated for $72 \mathrm{~h}$ with increasing doses of the IL-6 neutralizing monoclonal antibody siltuximab, and cell viability was assessed using the WST-1 reagent. Results were expressed as a percentage of the vehicle treated controls, which were arbitrarily set at $100 \%$. Median inhibitory siltuximab concentrations ( $\mathrm{IC}_{50}$ values) were calculated from the dose-response curve using GraphPad Prism software, and are the mean of three experiments. Bars represent the standard deviation (SD). (B) KAS-6/1 cells were pretreated with either siltuximab or the F105 control antibody at $0.05 \mu \mathrm{g} / \mathrm{ml}$ for $24 \mathrm{~h}$, followed by addition of melphalan (Mel) at the concentrations indicated for $48 \mathrm{~h}$. The WST-1 assay was used to assess cell viability, which was expressed as a percentage of the F105 isotype matched, antibody-treated control. All data represent the means of three experiments, bars indicate SD, and significance was evaluated with the $t$-test. Significant values at $P<0.05$ are indicated with '*', while $P<0.01$ is indicated by '**'. (C) INA-6 cells were pretreated with either siltuximab or F105 at $0.05 \mu \mathrm{g} / \mathrm{ml}$ for $24 \mathrm{~h}$, then treated with melphalan, and analysed as described in the legend to panel B. (D) ANBL-6 cells were pretreated with either siltuximab or F105 at $1.0 \mu \mathrm{g} / \mathrm{ml}$ for $24 \mathrm{~h}$, and then treated with melphalan and analysed as described in the legend to panel B. 
(A)
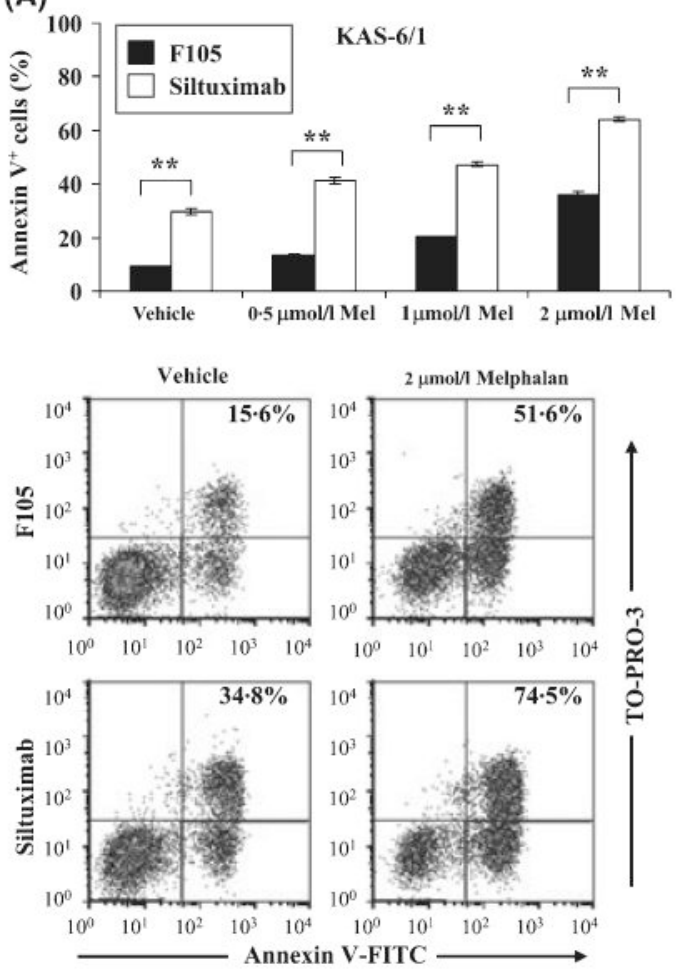

(B)
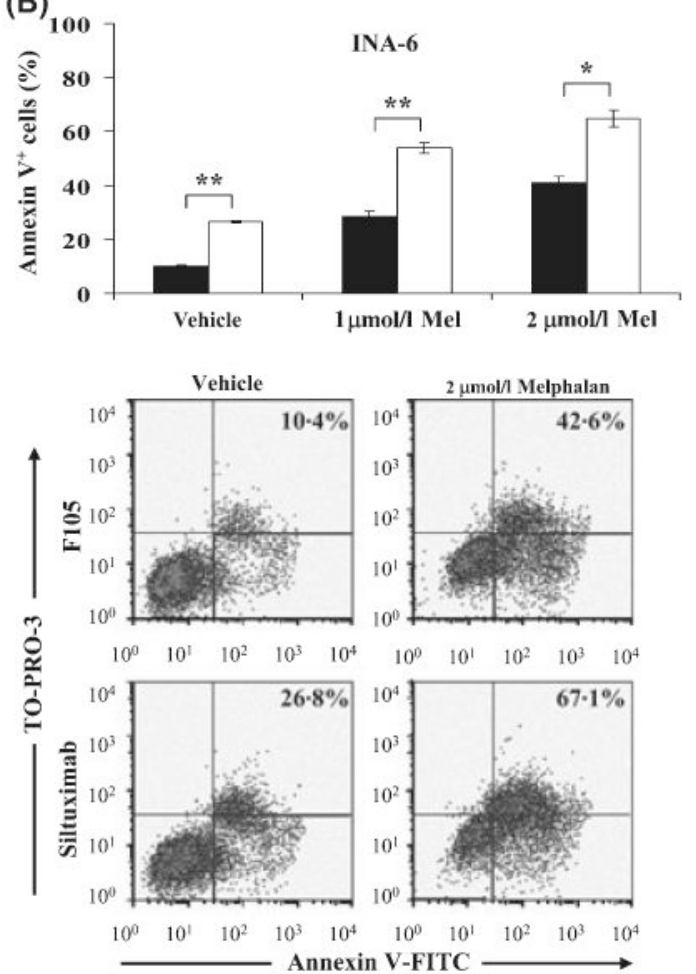

Fig 2.

IL-6 blockade with siltuximab increases melphalan-induced apoptosis. (A) KAS-6/1 cells were pretreated with $0.5 \mu \mathrm{g} / \mathrm{ml}$ siltuximab or F105 for $24 \mathrm{~h}$, followed by treatment with melphalan at the indicated concentrations for $48 \mathrm{~h}$. Apoptosis was measured by flow cytometry on cells stained with FITC-conjugated Annexin V and the DNA binding dye TOPRO-3. The bar graph (upper panel) presents the mean proportion of Annexin $\mathrm{V}^{+}$cells from two replicates, which are representative of three independent experiments. Bars indicate SD, significance was evaluated with the $t$-test. $*, P<0.05, * * P<0.01$. In the lower panel, a representative FACS profile from one experiment with $2 \mu \mathrm{mol} / \mathrm{l}$ melphalan is shown, and the percentage of cells that were Annexin $\mathrm{V}^{+}$(right upper + right lower quadrants) is indicated in the upper right. (B) INA-6 cells were pretreated with $0 \cdot 1 \mu \mathrm{g} / \mathrm{ml}$ siltuximab or F105 for $24 \mathrm{~h}$, then treated with melphalan, and data were acquired, analysed, and presented as above. 
(A)
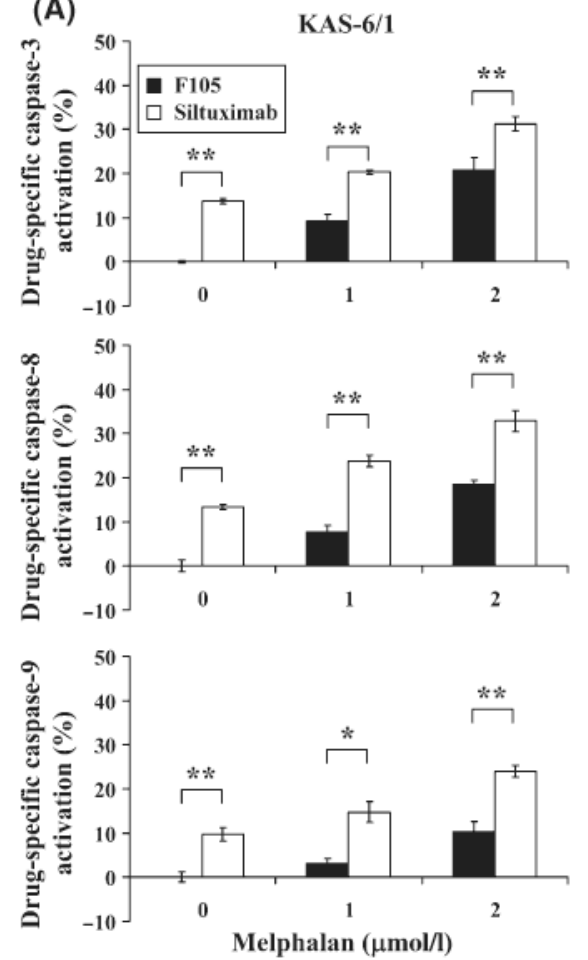

(B)
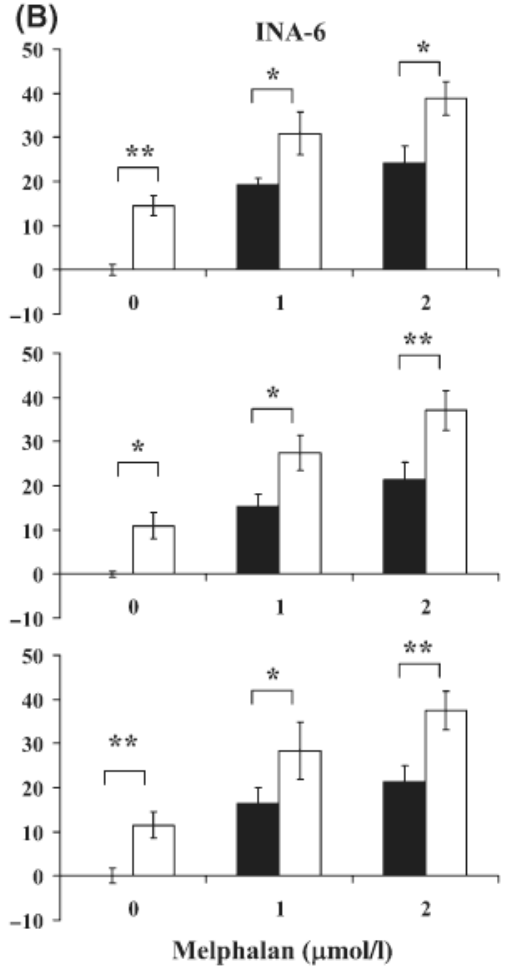

Fig 3.

Siltuximab enhances activation of the extrinsic and intrinsic apoptotic pathways in combination with melphalan. (A) KAS-6/1 cells were pretreated with siltuximab or F105 at $2.5 \mu \mathrm{g} / \mathrm{ml}$ for $24 \mathrm{~h}$, after which melphalan was added for $48 \mathrm{~h}$. To measure caspase activation, the cells were incubated for $30 \mathrm{~min}$ with irreversible caspase-3 (FITC-DEVDFMK, upper panel), caspase-8 (FITC-IETD-FMK, middle panel), or caspase-9 (FITCLEHD-FMK, lower panel) inhibitors, which bound the activated caspases, and then analysed by flow cytometry. Drug-specific caspase activation was calculated using the formula: [(\% FITC positive cells in treated sample-\% FITC positive cells in vehicle control sample)/ $(100-\%$ FITC positive cells in vehicle control sample $)] \times 100$. Bar graphs indicate the mean drug-specific caspase activation from three independent experiments, together with the SD. $*, P<0.05, * * P<0.01$ by the $t$-test. (B) INA- 6 cells were pretreated with siltuximab or F105 at $0 \cdot 1 \mu \mathrm{g} / \mathrm{ml}$ for $24 \mathrm{~h}$, then treated with melphalan, and data were acquired, analysed, and presented as above. 

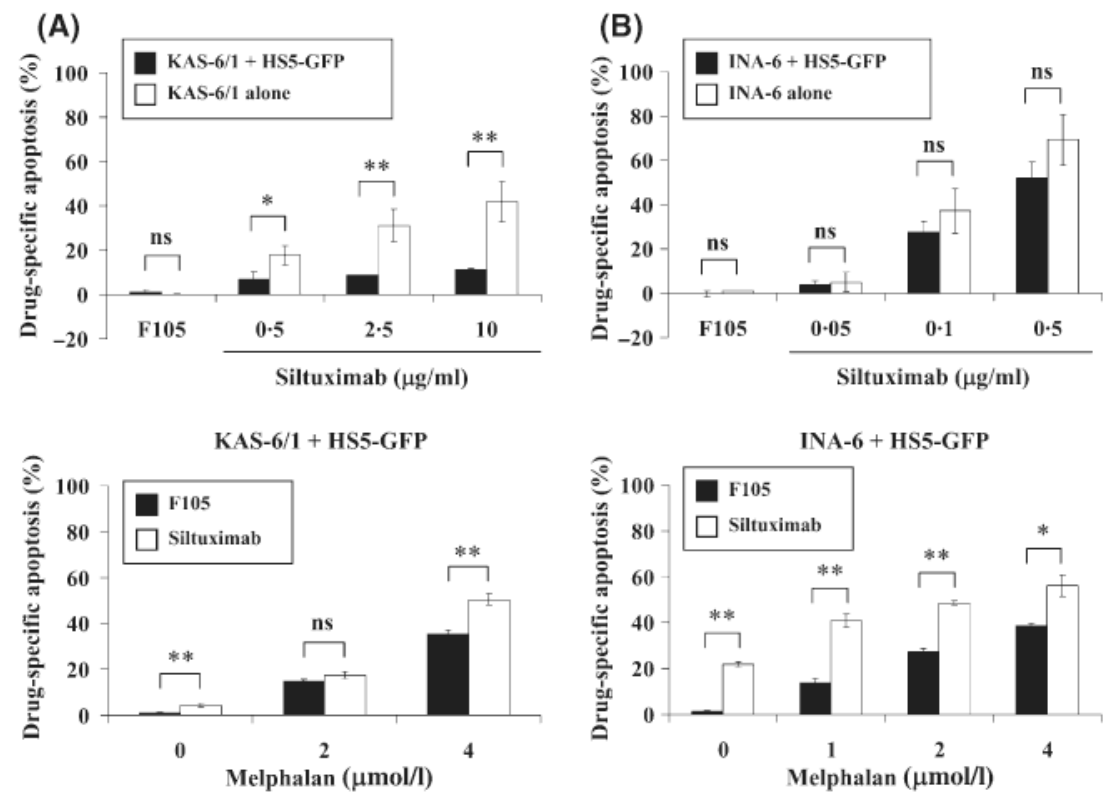

Fig 4.

Siltuximab enhances melphalan cytotoxicity in the presence of stroma. (A) KAS-6/1 cells were plated either alone or on top of adhered HS5-GFP stromal cells and allowed to attach overnight (upper panel). Cultures were then treated with the indicated concentrations of siltuximab for $72 \mathrm{~h}$, harvested by trypsinizing to collect all cells, and stained with PEconjugated Annexin V and the DNA dye TO-PRO-3. A total of 10000 events were analysed by flow cytometry to detect the proportion of cells undergoing programmed cell death. Stromal cells were separated from the myeloma cells by their intense green fluorescence. Drug-specific apoptosis was calculated using the equation: [(\% Annexin $\mathrm{V}$ positive cells in treated sample-\% Annexin V positive cells in vehicle control)/(100-\% Annexin V positive cells in vehicle control) $] \times 100$. Bar graphs indicate the mean drug-specific apoptosis from three independent experiments, along with the SD, with 'ns' indicating a trend that was not statistically significant, ' $*$ ' indicating a $P<0.05$, and ' $* *$ ' indicating a $P<0.01$ by the $t$-test. In the lower panel, KAS-6/1 cells were pretreated with siltuximab or F105 for $24 \mathrm{~h}$ at $10 \mu \mathrm{g} /$ $\mathrm{ml}$ in the presence of stromal cells, followed by the indicated concentrations of melphalan for another $48 \mathrm{~h}$. They were then processed, analysed, and data are presented as indicated above. Positive control experiments were performed with KAS-6/1 or INA- 6 cells treated with vehicle or dexamethasone either in the absence or presence of HS5-GFP cells, and demonstrated the ability of these stromal cells to protect myeloma cells from apoptosis (data not shown). (B) INA-6 cells were plated either alone or on top of adhered HS5-GFP stromal cells and allowed to attach overnight (upper panel). Cultures were then treated with the indicated concentrations of siltuximab for $72 \mathrm{~h}$, then harvested, stained with FITCconjugated Annexin V and TO-PRO-3, and analysed as described above. The data are presented as indicated in panel A. In the lower panel, INA-6 cells were pretreated with siltuximab or F105 at $0 \cdot 1 \mu \mathrm{g} / \mathrm{ml}$ in the presence of stromal cells for $24 \mathrm{~h}$, followed by the indicated concentrations of melphalan for another $48 \mathrm{~h}$. They were then processed and analysed, and the data are presented as indicated in panel A above. 

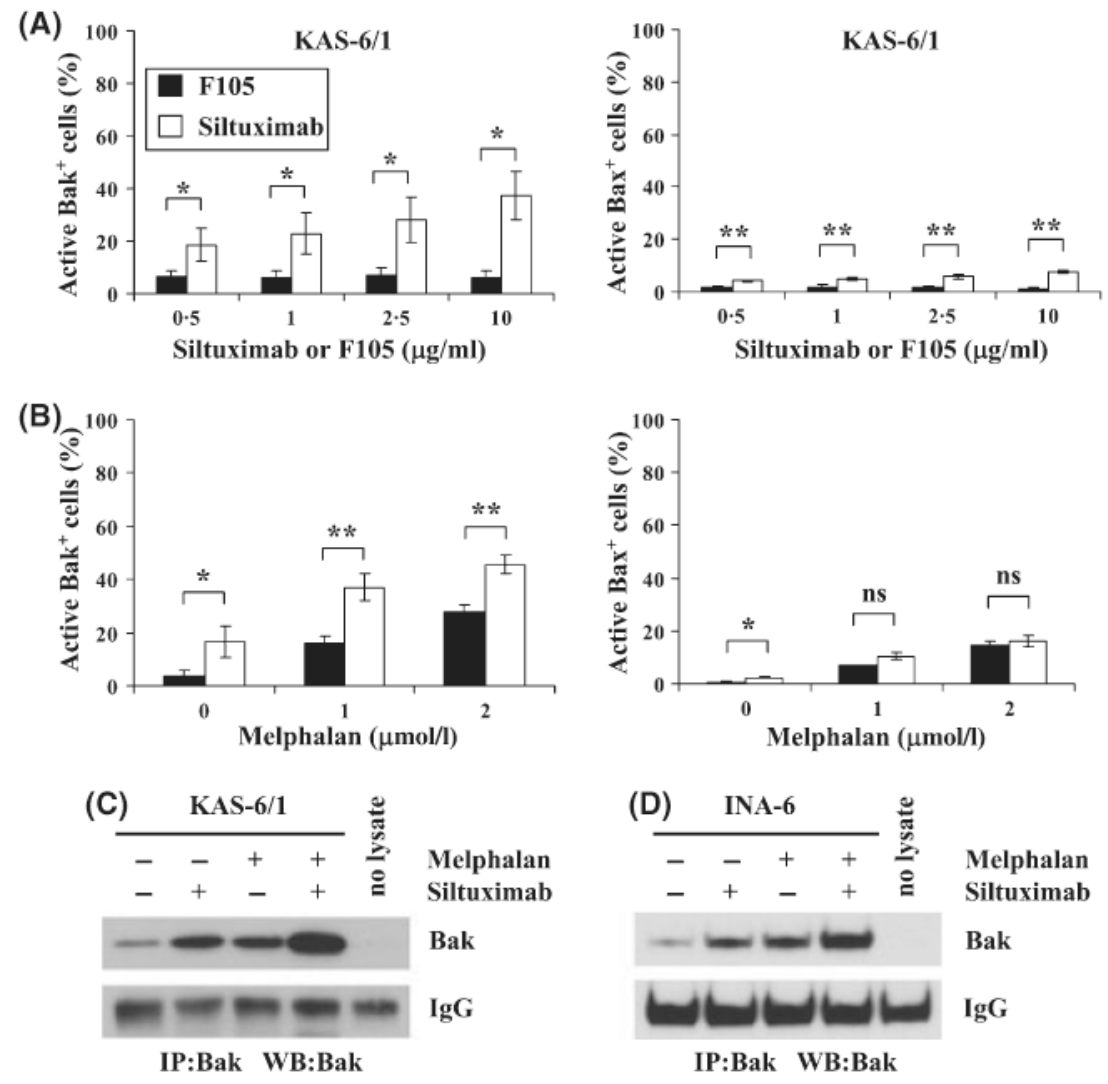

Fig 5.

Bak and Bax are activated by siltuximab and melphalan. (A) KAS-6/1 cells were treated with the indicated concentrations of siltuximab or F105 control antibody for $72 \mathrm{~h}$. They were then permeabilized and exposed to primary antibodies raised against the active forms of Bak (left panel) or Bax (right panel), followed by an Alexa Fluor ${ }^{\circledR} 488$ conjugated secondary antibody. Fluorescence was detected by flow cytometry. The percentage of cells with activated Bak or Bax is graphed as the mean of three independent experiments. Error bars indicate the SD, with ' $*$ ' indicating a $P<0.05$, and ' $* *$ ' indicating a $P<0.01$ by the $t$-test. (B) KAS-6/1 cells were pretreated for $24 \mathrm{~h}$ with $1 \mu \mathrm{g} / \mathrm{ml}$ of either siltuximab or F105, followed by melphalan at the indicated concentrations for $48 \mathrm{~h}$. Bak (left panel) or Bax (right panel) activation was then assayed, analysed, and presented as described above. Error bars indicate the SD, with 'ns' indicating a trend that did not reach statistical significance, ' $*$ ' indicating a $P<0.05$, and ' $* *$ ' indicating a $P<0.01$ by the $t$-test. (C) KAS-6/1 cells were pretreated with $2.5 \mu \mathrm{g} / \mathrm{ml}$ of either siltuximab (+lanes) or F105 (-lanes) for $24 \mathrm{~h}$, followed by either vehicle or $2 \mu \mathrm{mol} / \mathrm{l}$ melphalan for $48 \mathrm{~h}$. Cells were then lysed in buffer containing $1 \%$ CHAPS, and extracts were subjected to immunoprecipitation with an antibody that recognizes only the activated form of Bak. Immunoprecipitated Bak and the IgG heavy chain were then detected by Western blotting. A representative Western blot is shown from one of two independent experiments. (D) INA-6 cells were pretreated with $0 \cdot 1 \mu \mathrm{g} / \mathrm{ml}$ of either siltuximab (+lanes) or F105 (-lanes) for $24 \mathrm{~h}$, followed by either vehicle or $2 \mu \mathrm{mol} / \mathrm{l}$ melphalan for $48 \mathrm{~h}$. Cells were then subjected to immunoprecipitation to detect their content of activated Bak as described above. 


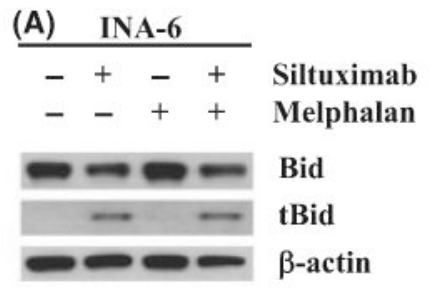

(B)

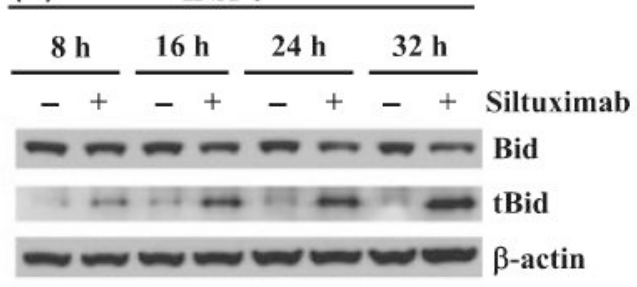

(C) KAS-6/1

Control $1 \mu \mathrm{mol} / 12 \underline{2 m o l} / 1$ Melphalan

-+-+-+ Siltuximab

$-m-20-$ p-Akt

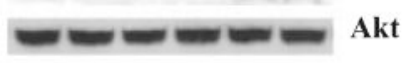

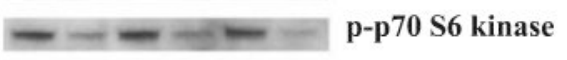

----- p70 S6 kinase

$\underline{m-a c t i n}$

$\omega-\ldots$ p-4E-BP1

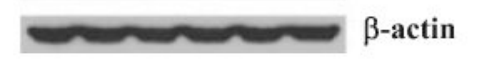

(D) INA-6



Fig 6.

Siltuximab activates Bid and reduces the activation status of the Akt pathway. (A) INA-6 cells were pretreated with $0 \cdot 1 \mu \mathrm{g} / \mathrm{ml}$ siltuximab (+lanes) or F105 (-lanes) for $24 \mathrm{~h}$ followed by $48 \mathrm{~h}$ with $2 \mu \mathrm{mol} / \mathrm{l}$ melphalan or vehicle control. Bid and tBid were detected in cellular lysates by Western blotting. A representative Western blot is shown from one of two independent experiments. (B) INA-6 cells were treated with $0.5 \mu \mathrm{g} / \mathrm{ml}$ siltuximab (+lanes) or F105 (-lanes) for the indicated times. Cellular lysates were probed by Western blotting for Bid and tBid. A representative Western blot is shown from one of two independent experiments. (C) KAS-6/1 cells were simultaneously exposed to $0.5 \mu \mathrm{g} / \mathrm{ml}$ of either siltuximab (+lanes) or F105 (-lanes), and either vehicle control or melphalan at the indicated concentration. Cellular lysates prepared from cells treated as above for $8 \mathrm{~h}$ were probed by Western blotting to detect the levels of Akt, phospho-Akt, p70 S6 kinase, and phospho-p70, as well as $\beta$-actin as a loading control. Lysates prepared from cells treated as above for $24 \mathrm{~h}$ were probed by Western blotting to detect the levels of phospho-4E-BP1. A representative Western blot is shown from one of two independent experiments. (D) INA-6 cells were treated and analysed as described above in the legend to panel $\mathrm{C}$. 
(A)

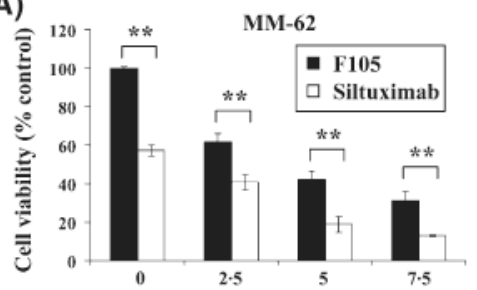

(B)

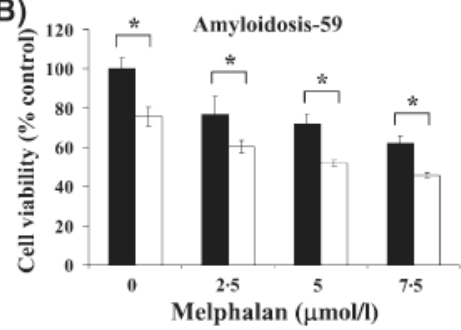

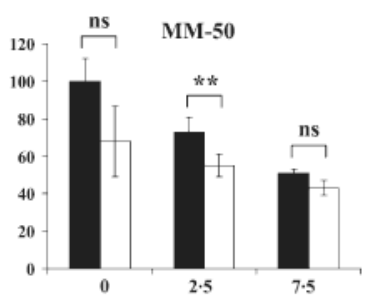

(C)



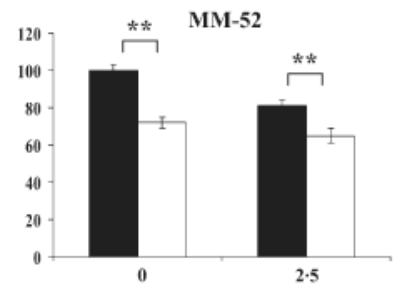

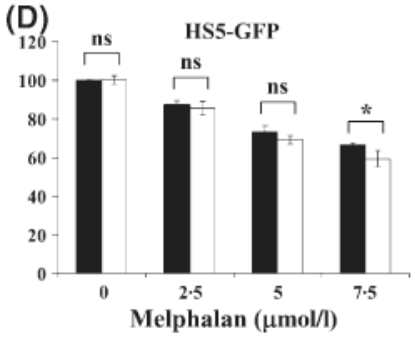

Fig 7.

Siltuximab and melphalan are active against primary plasma cells. (A) Primary CD138 ${ }^{+}$ plasma cells isolated from the bone marrow aspirates of three patients with multiple myeloma were pretreated with either $10 \mu \mathrm{g} / \mathrm{ml}$ siltuximab or F105 control antibody for $24 \mathrm{~h}$. They were then exposed to the indicated concentrations of melphalan or vehicle for another $48 \mathrm{~h}$. Cell viability was then measured using the WST-1 reagent, and is presented as the percent viability compared to the vehicle-treated controls (F105 plus acid saline/acid ethanol). All data represent the mean of a single experiment performed in triplicate, with bars indicating SD. Significance was evaluated with the $t$-test, with 'ns' indicating a trend that did not reach statistical significance. Significant values at $P<0.05$ are indicated with '*', while $P<0 \cdot 01$ is indicated by '**'. (B) Primary CD138 ${ }^{+}$plasma cells isolated from the bone marrow aspirate of one patient with amyloidosis were evaluated as described in panel A. Error bars indicate the SD, ' $*$ ' indicating a $P<0.05$, and ' $* *$ ' indicating a $P<0.01$ by the $t$-test. (C) Primary CD138 $8^{+}$plasma cells isolated from the bone marrow aspirate of one patient with monoclonal gammopathy of undetermined significance (MGUS) were evaluated as described in panel A. (D) The HS5-GFP stromal cell line was pretreated with either 10 $\mu \mathrm{g} / \mathrm{ml}$ siltuximab or F105 control antibody for $24 \mathrm{~h}$, and then treated with melphalan and analysed as described in panel A. 


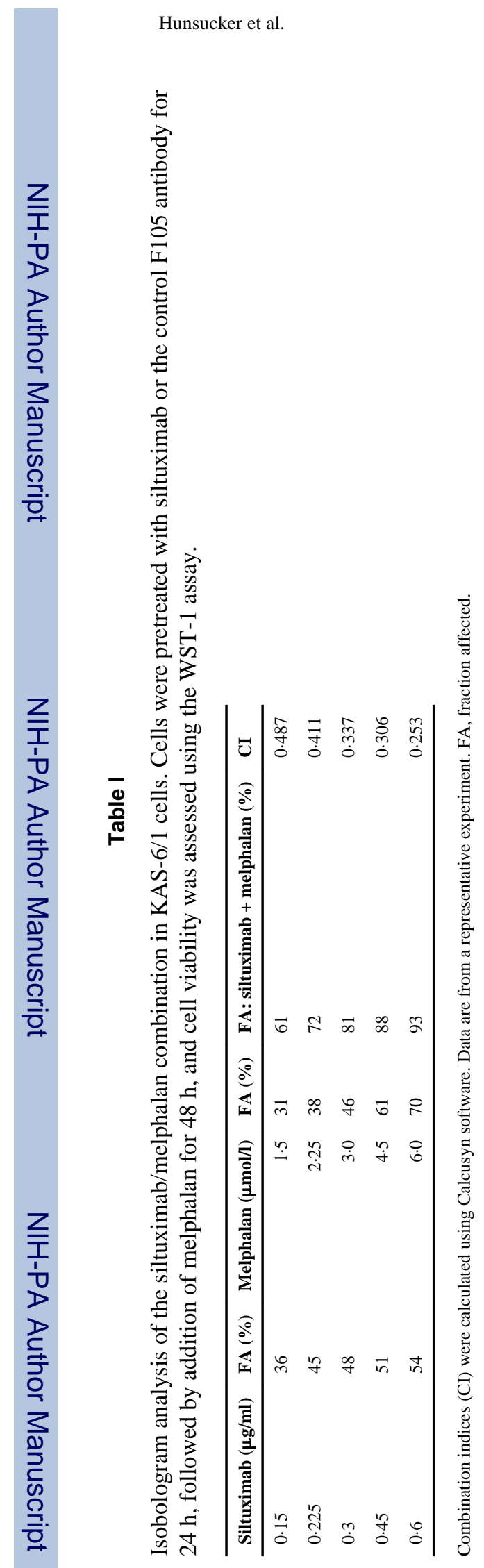

Br J Haematol. Author manuscript; available in PMC 2012 July 24. 